\title{
Static Deformation of Low Structure HAF Black-Loaded (SBR+NR) Rubber Blend
}

\author{
A.M.Y. El-Lawindy \\ Department of Physics, Faculty of Science, Suez Canal University. Ismailia, Egypt
}

The stress-strain behavior of different concentrations of low-structure high abrasion furnace black (HAF-LS)- loaded rubber blend of styrene butadiene rubber and natural rubber $(S B R+N R)$ of equal parts was measured. Modulii of elasticity and the $n$ - measure of such blends were calculated using different approaches. An anomaly, of modulus of elasticity, found at 50 phr may be attributed either to what is called compact structure and!or to the early crystallization of natural rubber (NR) in the blend. These assumptions are confirmed through the measurement of the swelling factor as a function of time of swelling in kerosene. 


\section{Introduction:}

It is known that NR crystallizes under stretching, so that it resists deformation and enhances its strength while SBR does not crystallize. Mixtures of NR and SBR are quite often used in order to get desired technological properties.

Our previous work [1] used the equation for the true stress- true strain at simple tension suggested in the Blatz et al. [2],

$$
\bar{\sigma}=\frac{2 \mathrm{G}_{\mathrm{o}}}{\mathrm{n}}\left(\lambda^{\mathrm{n}}-\lambda^{-\mathrm{n} / 2}\right)
$$

where $\sigma$ is the true stress and $G$ is the shear modulus at the origin, $\lambda=1$, and $\lambda$ is the extension ratio, to ascertain experimental data of different rubber affected by different types of carbon black. It was found that, the $\mathrm{n}$ measure was always a material constant of the host rubber. The values for SBR and NR were 3.5 \pm 0.4 and $2.3 \pm 0.2$, respectively and the modulus of elasticity, at simple tension, was found non-linear as a function of carbon black concentration.

In the present work, HAF-LS, of different concentration, was compounded with a blend of equal parts of SBR and NR, with the aim of studying the behavior of the n-measure and the elasticity modulus of such new composite.

On the other hand, the swelling in kerosene, as a function of time, test was performed on all samples to elucidate the internal structure of the new composites. One useful parameter such as, the swelling factor was calculated and used to assist in the explanation of the stress-strain data.

\section{Experimental Technique:}

The samples investigated in this study, were mixtures of equal parts of NR and SBR-1502 as a host rubber compounded with different concentrations of I-IAF-LS ( $85 \mathrm{~m}^{2} / \mathrm{g}$ surface area and $255 \AA$ particle diameter), according to the recipe shown in Table 1.

Table 1: The recipe of the samples used.

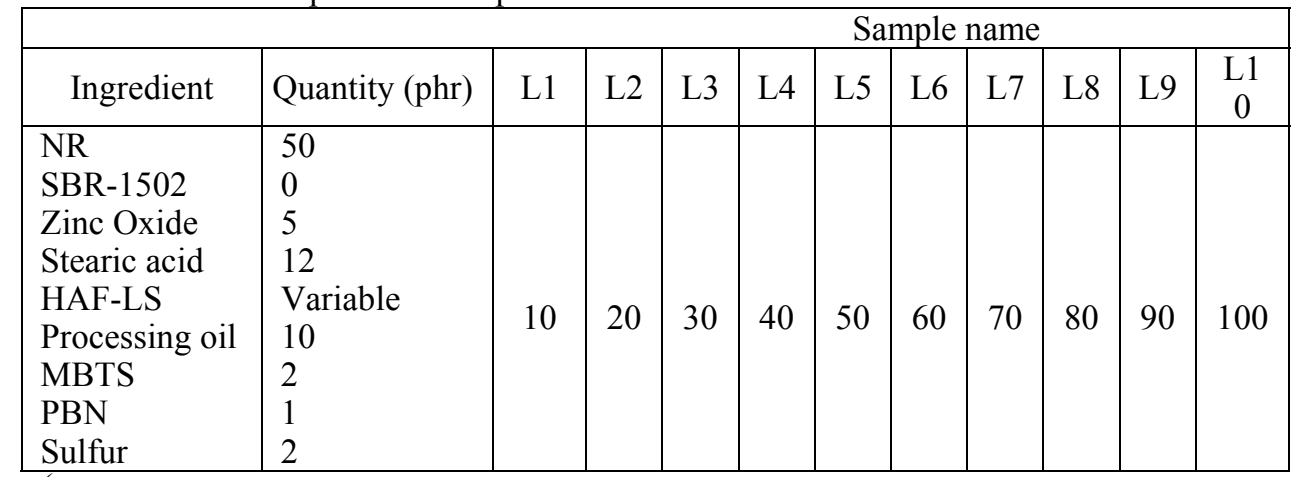

(phr is part per hundred parts of rubber by weight, MBTS is Dibenzthiazyl disulphide, and PBN is Pheny1- a possible carcinogenic compound.) 
Ingredients of the rubber blend were mixed on a 2-roll laboratory mill of $170-\mathrm{mm}$ diameter, 300-mm length ,the speed of slow roll being $18 \mathrm{rpm}$ and gear ratio 1.4. The ingredients were added in the order as shown in Table 1. The compounded rubber was left for 24 hours before vulcanization. The vulcanization process was performed at $143^{\circ} \mathrm{C}$ under a pressure of $4 \mathrm{Kg} / \mathrm{cm}^{2}$ for 30 minutes. To insure reproducibility, the samples were conditioned at $7^{\circ} \mathrm{C}$ for 50 days [3].

The test samples were strips of $2 \mathrm{~cm}$ working length and of $\sim 4 \mathrm{~mm}^{2}$ cross-sectional area.

Stress- strain measurements were performed using a tensile test machine (AMETEK, USA). A digital force gauge (Hunter Spring ACCU Force II, $0.01 \mathrm{~N}$ resolution, USA) connected to a microprocessor was used to measure extension force. A home made motor attachment was used to control the strain rate through a gearbox. The strain rate was preset using a variable DC power supply, and was measured using a micro-switch attached to the apparatus wheel. The accuracy of strain measurement was about $0.1 \mathrm{~mm}$. The strain rate throughout the experiment was fixed at $1 \mathrm{~mm} / \mathrm{sec}$.

\section{Results and Discussion:}

Figure 1 shows the stress-strain behavior of rubber blends. In Table 2 the obtained mechanical parameters which are modulus of elasticity $\mathrm{Y}\left(\mathrm{N} / \mathrm{rn}^{2}\right)$ true stress at break, ab $(\mathrm{N} / \mathrm{rn}$ and strain at break, $\mathrm{Cb}$, are listed. $\mathrm{Y}\left(\mathrm{N} / \mathrm{rn}^{2}\right)$ was calculated as the slope of true stress-extension ratio curves up to $\lambda=2$.

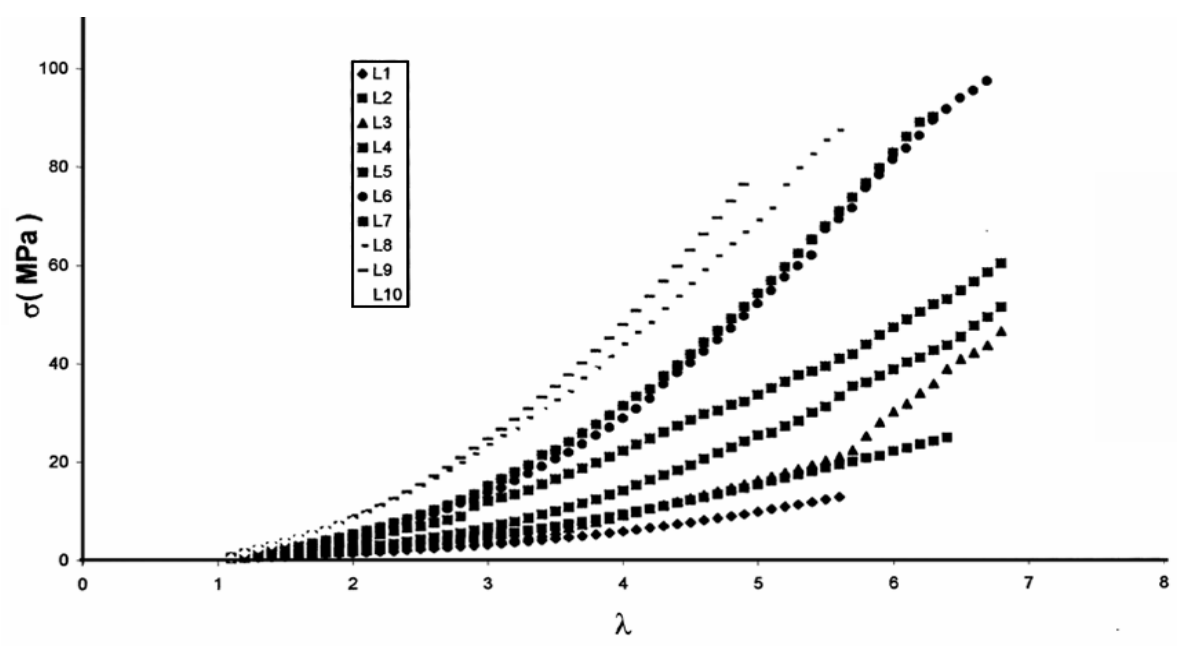

Fig. (1): The true stress-true strain behavior for all samples. 
Table (2): A list of resulted mechanical parameters obtained from true stressstrain characteristics (Figure 1).

\begin{tabular}{|c|c|c|c|}
\hline Sample & Y $(\mathrm{MPa})$ & $\sigma_{\mathrm{b}}(\mathrm{MPa})$ & $\varepsilon_{\mathrm{b}}$ \\
\hline L1 & 1.17 & 21.6 & 6.1 \\
\hline L2 & 1.57 & 29.4 & 6.1 \\
\hline L3 & 1.55 & 3.7 & 6.2 \\
\hline L4 & 2.29 & 62.0 & 6.3 \\
\hline L5 & 3.94 & 76.0 & 6.6 \\
\hline L6 & 4.05 & 95.4 & 5.6 \\
\hline L7 & 4.98 & 90.1 & $5 / 3$ \\
\hline L8 & 8.85 & 87.3 & 4.6 \\
\hline L9 & 8.08 & 88.3 & 4.1 \\
\hline L10 & 7.98 & 54.4 & 3.3 \\
\hline
\end{tabular}

The stress-strain, equation 1, is approximated by Malkin et al. [4], to

$$
\log \frac{2 \bar{\sigma}}{3 \mathrm{E}_{\mathrm{o}}}=\mathrm{n} \log \lambda-\log \mathrm{n},
$$

where $E_{o}$ is the initial value of the elastic modulus in un-axial tension, and suggested a graphical method for the determination of the constants $\mathrm{n}$ and $\mathrm{E}$ by constructing a plot of $\log \sigma$ versus $\log \lambda$, (Figure 2). These data, were fitted using linear least square method. The correlation coefficients, $\mathrm{R}^{2}$ were found not less than 0.9. The n-measure was obtained from the slopes, whereas E was obtained from the intercept of the fitted curves.

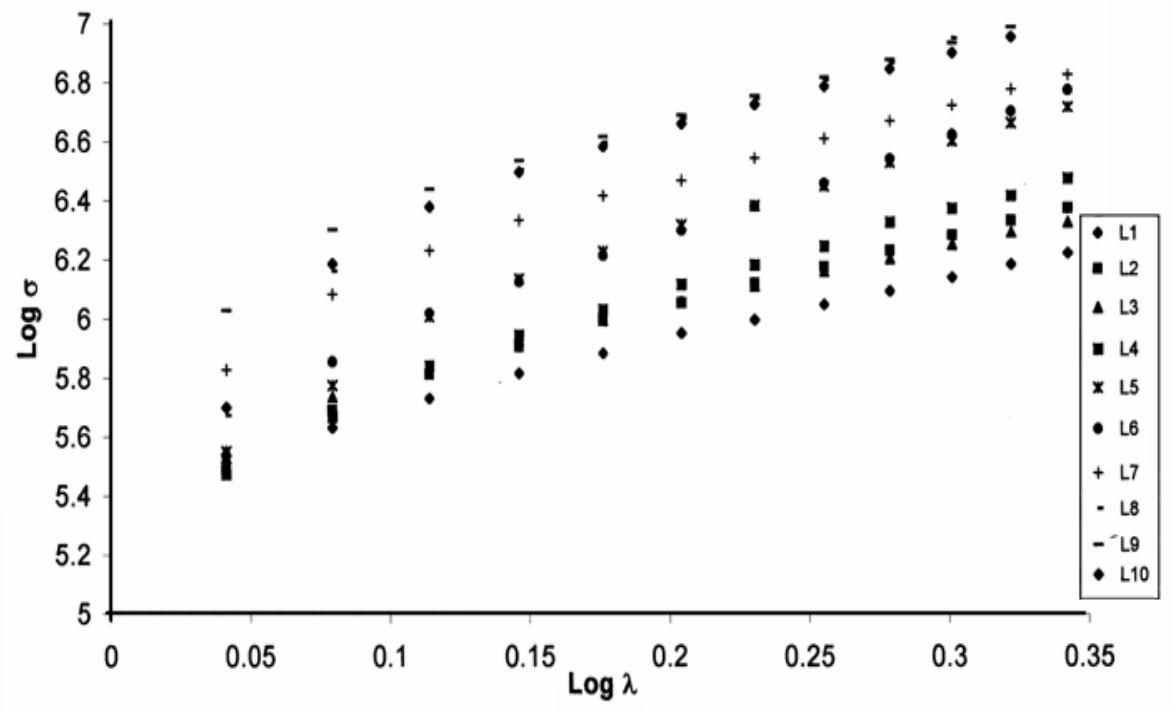

Fig. 2: The behavior of $\log$ versus $\log \lambda$. 
An average value of $n=2.54 \pm 0.21$, was obtained. Considering that the blend contains the same parts from both types of rubber, it is interesting to note that this $\mathrm{n}$ value approximately equals the average value of both individual $\mathrm{NR}=2.30 \pm 0.23$ and $\mathrm{SBR}=3.50 \pm 0.35$ rubber respectively [1]. This result raises a question about the value of $\mathrm{n}$ if blending rubber of different concentration is considered.

On the other hand, the rubbery modulus has been calculated from different approaches of stress-strain data at simple tension, $\lambda=2$.

According to kinetic theory [5-7] of rubber elasticity, the stress-strain takes the form

$$
\bar{\sigma}=\mathrm{G}_{1}\left(\lambda^{2}-\lambda^{-1}\right)
$$

where $\mathrm{G}_{1}$ represents the rubbery modulus and $\bar{\sigma}$ represents the true stress. Zang et al. [8] used an equation of the form;

$$
\bar{\sigma}=\sigma_{\mathrm{o}}+\mathrm{G}_{2}\left(\lambda^{2}-\lambda^{-1}\right)
$$

where $\sigma_{\mathrm{o}}$ was found to depend only on the chemical nature of rubber and may be ascribed to local interaction of the segments of rubber. $G_{2}$ was found to depend only on the degree of cross-linking and seems to represent the rubbery modulus of the kinetic theory

Figure 3 shows the relation between true stress, $\sigma\left(\mathrm{N} / \mathrm{rn}^{2}\right)$ and $\left(\lambda^{2}-\lambda^{-1}\right)$, up to $\lambda=2$. The parameter $G_{1}$ was obtained from linear least squares fitting at intercept equals zero, equation 3 , whereas G2 was obtained at intercept equals to $\sigma_{0}$, equation 4 . The values of $\sigma_{\mathrm{o}}$ were found negative except at $100 \mathrm{phr}$ loading. The fitting correlation coefficient, $\mathrm{R}$ of the linear least squares fitting, for both equations, were rarely less than 0.98 . Figure 4 shows the behavior of $\mathrm{G}=\mathrm{Y} / 3, \mathrm{G}_{\mathrm{o}}=\mathrm{E}_{0} / 3 . \mathrm{G}_{1}$ and $\mathrm{G}_{2}$ as a function of black concentration. It is seen that their behavior with concentration is similar in the four cases. Also, one may consider that $\mathrm{G}_{1}$ and $\mathrm{G}_{2}$ represent shear modulus in the simple kinetic theory, equation 3 .

The anomaly at $50 \mathrm{phr}$ HAF-LS concentration may be attributed either to the formation of what is called compact structure of carbon black at $50 \mathrm{phr}$ or to an early crystallization of NR rubber inside the composites. Since NR tends to crystallize at small extension, one may expect an increase in the modulus of elasticity. As the concentration increases, the interaction between rubber chains atoms and surrounding medium increase. Rotational angle motion may then be suppressed during deformation and large amounts of energy are stored in backbone angles and bond length deformation. At higher concentration, the effect of reinforcement of SBR may predominate up to certain concentration, 90 
phr of HAF-LS. Above such concentration, the sample starts to become tougher. This decrease of $\mathrm{G}$ with increasing carbon concentration above $90 \mathrm{phr}$ may be attributed to the weak interaction between carbon particles upon the formation of carbon agglomerates.

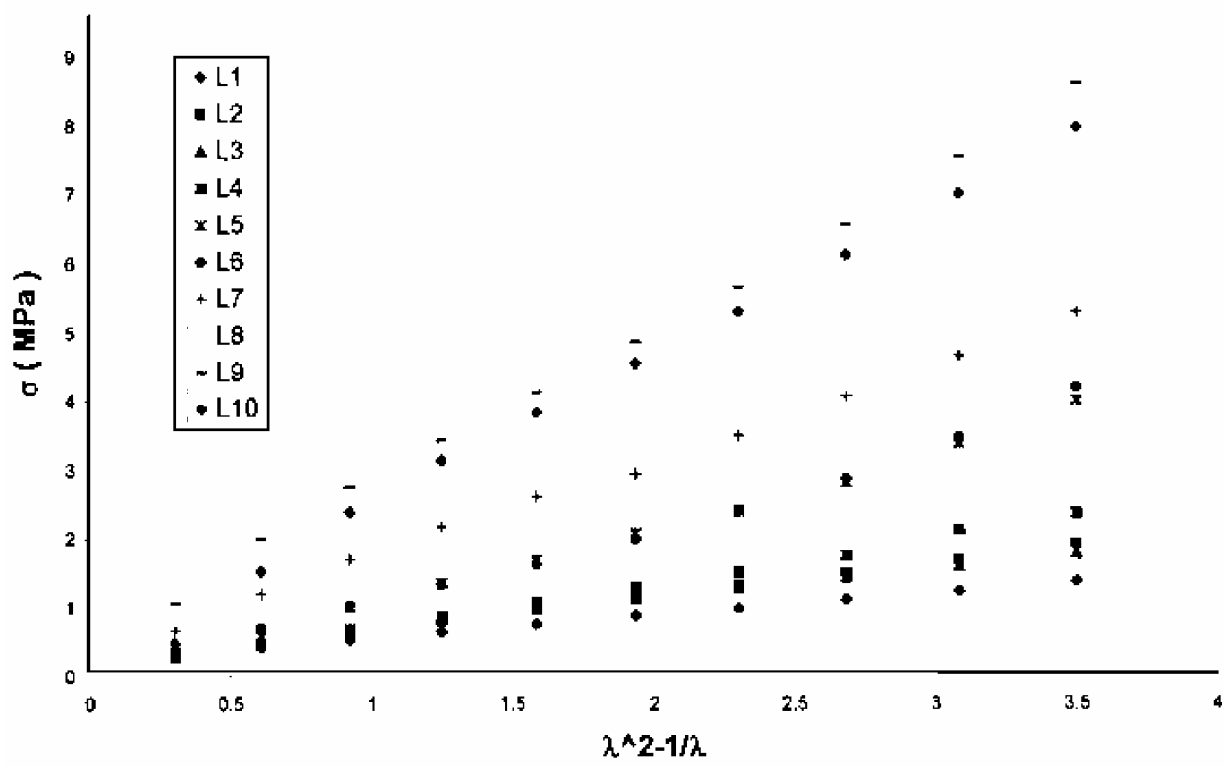

Fig. (3): The relation between true stress, $\left(\mathrm{N} / \mathrm{rn}^{2}\right)$ and $\left(\lambda^{2}-\lambda^{-1}\right)$ up to $\lambda=2$

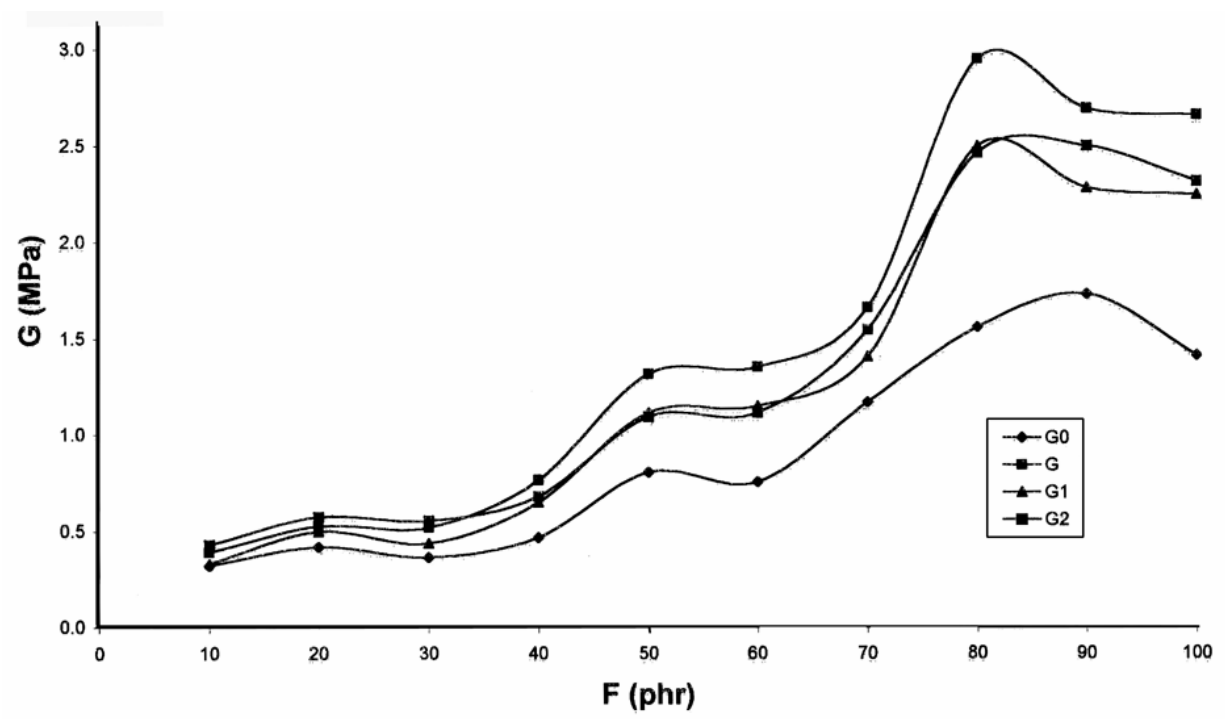

Fig. (4): The behavior of the modulus of elasticity, $G, G_{0}, G_{1}$ and $G_{2}$, as functions of carbon black concentration. 
To confirm these assumptions, swelling in kerosene as a function of time was performed. In this experiment, the swelling factor, $Q(t) \%$ was obtained as a function of time, (Figure 5).

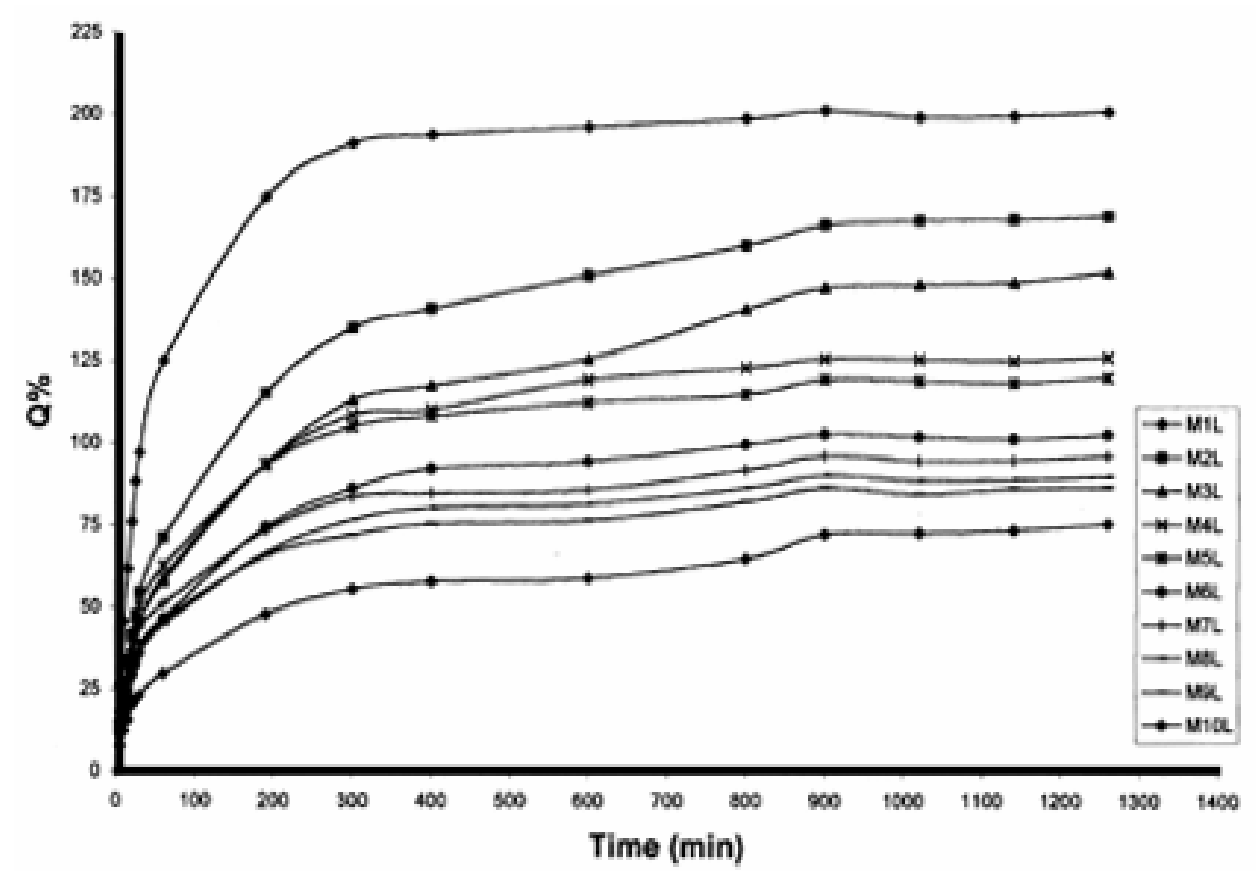

Fig. (5): The swelling factor, $Q(t) \%$, as a function of swelling time $t(\min )$ in kerosene.

It is known that carbon black does not dissolve in kerosene, and the host rubber may swell in kerosene. This means that the distance between carbon aggregates may be changed during swelling. Figure 6, represents the change in the average values of maximum swelling factor, $\mathrm{Q}_{\mathrm{m}} \%$, as a function of carbon blacks concentration. One can observe that the $\mathrm{Q}_{\mathrm{m}} \%$, in general, decreases by increasing carbon black concentration, denoting an open aggregate carbon structure, which has a high bulk. But at 50-phr concentration Q is slightly different from that at $40 \mathrm{phr}$, which means that there is a slight change in the distance between carbon black particle [9]. This may indicate clustered aggregates, which are more compacts and/or increased interactions inside the rubber composite. Also, the modulus of elasticity of samples containing $50 \mathrm{phr}$ and $60 \mathrm{phr}$ are nearly the same, (Table 2), whereas the value of the sample containing $40 \mathrm{phr}$ is lower than their value,. This may explain the anomaly, at 5O-phr carbon black concentration, observed in Figure 4. 


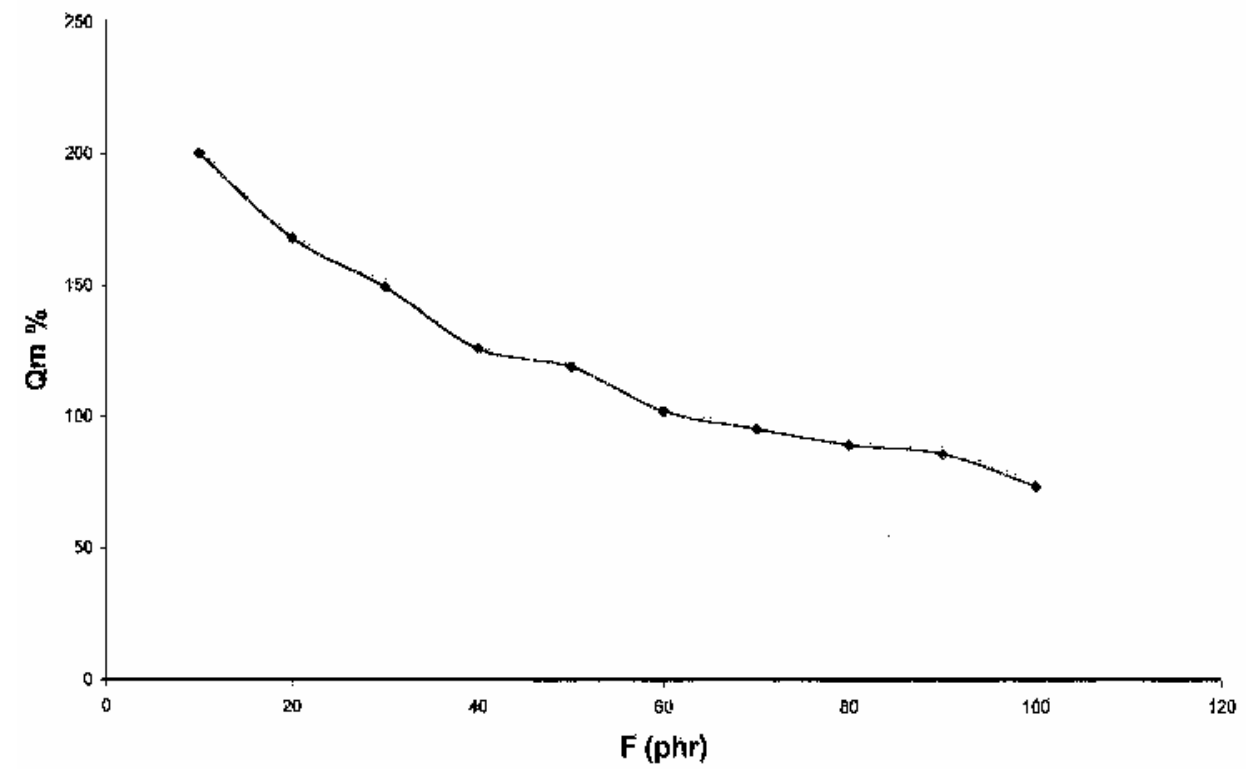

Fig. (6): The behavior of the average value of the maximum swelling factor $\mathrm{Q}_{\mathrm{m}} \%$ as a function of carbon black concentration, $F(\mathrm{phr}$.)

This behavior was observed [1] for fast extrusing furnace black FEF/SBR composite, which are loaded with different concentrations of FEF carbon black.

The anomaly at $80 \mathrm{phr}$ concentration is attributed to the sample britteleness at such high fillerconcentration.
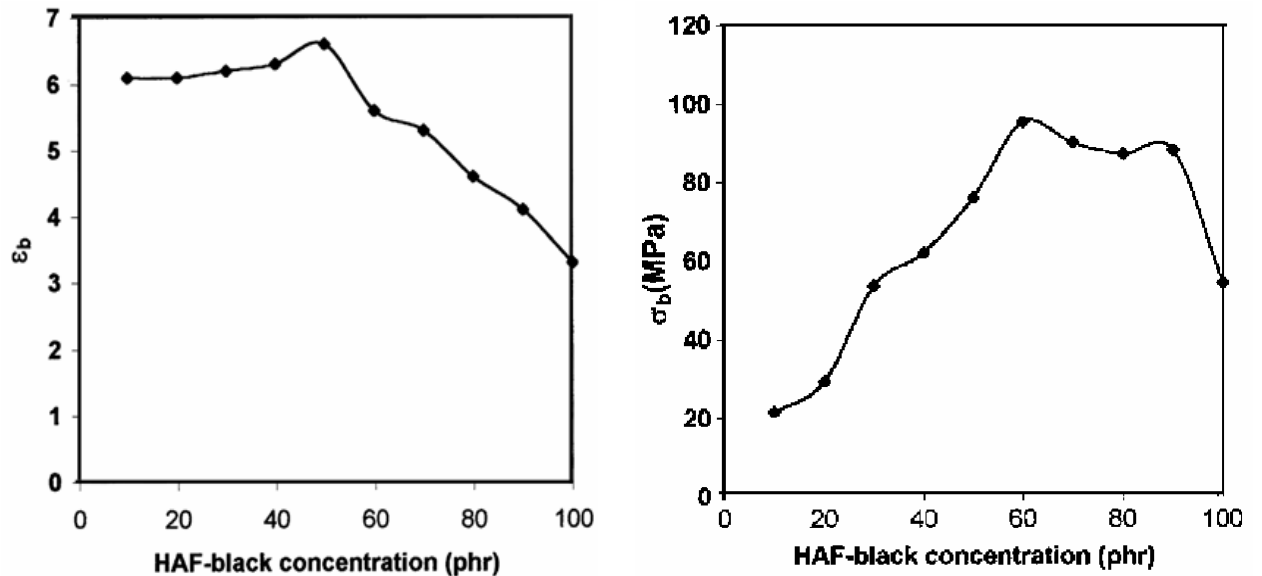

Fig. (7): The behavior of the true stress at break, $\sigma_{b}\left(N / \mathrm{m}^{2}\right)$ and strain at break, $\varepsilon_{\mathrm{b}}$, as functions of carbon black concentration 
The mechanical parameters, $\sigma_{\mathrm{f}}$ and $\varepsilon_{\mathrm{b}}$ are shown in Fig. 7. This figure shows an optimum strength at 60 phr of HAF-LS carbon black, after which a decrease is obtained. This behaviour may be attributed to a percolation concentration for such carbon black in the blend and/or to the crystallinity under stretching of NR in the blend. Above this concentration, the dilution effect of carbon black may take place. This may explain the gradual decrease of $\varepsilon_{\mathrm{b}}$.

\section{Conclusion:}

One may conclude that the n-measure is still a material parameter, even the host rubber is a mixture of two types of rubber. The n-measure was found to have the average value for that of SBR and NR individually. Future work should endeavour to find out the value of $\mathrm{n}$ at different concentration of both types of rubber in the blend.

The anomaly of modulus of elasticity at 5O-phr HAF-LS carbon black concentration is attributed to a compact structure and/or early crystallization of NR rubber inside the matrix at such concentration. This conclusion was confirmed through the measurement of the swelling factor as a function of time.

\section{References:}

1. A.M.Y. El-Lawmdy, ands.B.El-Guiziri, J. Phys. D, Appl. Phys., 33, 1894 (2000).

2. P.J. Blatz, S.C. Sharda and N.W. Tschoegl, Trans. Soc. Rheol. 18; 1, 145 (1974

3. E.M. Abdel- Bary, M. Amin and H.H. Hassan, J. Polymer Sci., Polym. Chem. Ed., 15, 197A (1977).

4. Y.A. Malkin, Y.U. Sabasi and V.P. Beghishev, Intern. J. Polymer Mater. 9, 1 (1981).

5. F.T. Wall, J. Chem. Phys. 11, 527 (1943).

6. P.J. Flory, "Principle of Polymer Chemistry" Come! Univ. Press Ithaca. N.Y. (1953).

7. H.M. James, and E. Guth, J. Chem .Phys. 11, 455 (1943).

8. Y. Zang, R. Muller and D. Froelich, J. Rheology, 30(6) 1165 (1986).

9. H.H. Hassan and G.M. Nasr, J. Macromol. Chem. A18(4), 535 (1982). 